\title{
Between Quality Assurance and Improvement: 25 Years of EQuiP Service (1991-2016)
}

\author{
Kalite Güvencesi ve Kalite Geliştirme Arasında: 25 Y1llık EQuiP Tarihçesi \\ (1991-2016)
}

Ulrik Bak Kirk $^{l}$, Vildan Mevsim ${ }^{* 2}$

\begin{abstract}
The European Society for Quality and Safety in Family Practice (EQuiP) is WONCA Europe's network for Quality Improvement and Patient Safety. It has formally been in service since 1991, with the aim of developing tools and methods for quality improvement in general practice in collaboration with GP research institutions.

In 2016, EQuiP is celebrating its $25^{\text {th }}$ Anniversary, which demonstrates an appropriate occasion for contemplating and commenting on the current quality and patient safety developments in the europe context of primary care. The organisational history of EQuiP can be divided into three major phases: Product phase (1991-2006), Reflecting phase (2006-2011) and Networking phase (2011-now). The first phase lasted from 1991-2006, and the main interest was to develop 'one size fits all' tools to assess and improve quality in primary health care.

The intermediate phase was from 2006-2011, where the focus for quality development switched from individual tools and an individualistic approach for decision making to health care systems and methods for planning and implementing change. The latest phase started in April 2011 and is still ongoing. During this period, the focal point shifted towards collaboration and involvement of stakeholders and networks rather than products.
\end{abstract}

Key Words: Patient safety, family medicine, quality improvement

\section{ÖZET}

1991 yılında kurulan Avrupa Aile Hekimliği Kalite ve Hasta Güvenliği Derneği (EQuiP), WONCA Avrupa Kalite Geliştirme ve Hasta Güvenliği Ağıdır. Genel pratisyenlik akademik birimleri işbirliğinde aile hekimliği uygulamasında kalite geliştirmeye yönelik araçlar ve yöntemler geliştirmek amacıyla kurulmuştur. 2016 yılı EQuiP'in 25. yıldönümünü olması nedeniyle tanıtım ve faaliyetlerin değerlendirilmesi açısından firsat olarak görülmüştür. EQuiP'in tarihi; Ürün aşaması (1991-2006), Yansıma aşaması (2006-2011) ve Ağ oluşturma aşaması (2011-şimdi) olarak üç ana aşamada incelenmiştir. Birinci aşama 1991'den 2006 yılına kadar devam etmiştir. Bu aşamada ana ilgi odağ birinci basamak sağlık hizmetlerinde kalite geliştirme ve değerlendirme için 'herkese uyan tek beden' araçlar geliştirmekti. Yansıma dönemi 2006-2011 yılları arasında gerçekleşmiştir. Bu dönemde kalite geliştirme, sağlık sistemleri için karar verme ve planlamada, uygulamanın değişiminde gerekli olan yöntemlere yönelik geliştirilen bireysel araçlar ve bireysel yaklaşımlara odaklanılmıştır. A ğ oluşturma aşaması Nisan 2011'de başlamış ve halen devam etmektedir. Bu dönemin odak noktası, ürünler yerine paydaşların ve ağların iş birliği ve katılımıdır. EQuip bu amaçlar doğrultusunda halen pek çok çalışma yürütmektedir.

Anahtar kelimeler: Aile hekimliği, hasta güvenliği, kalite geliştirme

Received Date / Geliş Tarihi: 18.01.2018, Accepted Date / Kabul Tarihi: 20.03.2018

${ }^{1}$ University of Copenhagen Faculty of Health and Medical Sciences Copenhagen DENMARK

${ }^{2}$ Dokuz Eylül Üniversitesi Tıp Fakultesi Aile Hekimligi AD Balcova Izmir TÜRKIYE

* Address for Correspondence / Yazışma Adresi: Vildan Mevsim, Dokuz Eylul Universitesi Tıp Fakultesi Aile Hekimligi AD Balcova İzmir TÜRKIYE, E-mail: vmevsim@gmail.com

Kirk UB, Mevsim V. Kalite Güvencesi ve Kalite Geliştirme Arasında: 25 Yıllık EQuiP Tarihçesi (1991-2016). TJFMPC, 2018; 12(2): 148-152. DOI: $10.21763 /$ tjfmpc.432552 


\section{GíRIŞ}

Avrupa Aile Hekimliği Kalite ve Hasta Güvenliği Derneği (EQuiP), WONCA Avrupa Kalite Geliştirme ve Hasta Güvenliği Ağıdır. Hollanda'lı araştırmacı Richard Grol tarafından kurulan EQuiP, 1991 'den beri çalışmalarını yürütmektedir. Genel pratisyenlik akademik birimleri işbirliğinde aile hekimliği uygulamasında kalite geliştirmeye yönelik araçlar ve yöntemler geliştirmek amacıyla kurulmuştur.

2016 y1lının EQuiP'in 25. yıldönümünü olması, Avrupa'da çeşitli ülkelerde birincil bakımda kalite ve hasta güvenliği konusunda sağlanan gelişmeleri değerlendirmek için bir firsat yaratmıştır.

WONCA Avrupa Ağ'larından bir olan EQuiP'nin kuruluş amacı, tüm Avrupa ülkelerinde, aile hekimliğinde hasta güvenliği ve bakım kalitesini en yüksek düzeye çıkarmak için katkıda bulunmak olarak belirlemiştir. EQuiP bunu başarmak için uzmanlık ve metodolojinin aktarılabileceği ve işbirliğinin sağlanabileceği bir yap1 oluşturmuştur. Bununla birlikte, birinci basamakta Kalite Geliştirme (QI), Kalite Yönetimi ve Geliştirme alanında projeler geliştirerek ve yürüterek katkıda bulunmaktadır.

Birinci basamakta kalite geliştirme ve güvenliği hasta bakım hizmetini iyileştirmek amacıyla, iyi klinik uygulama için hedeflerin belirlenmesi ve performansın değerlendirilmesine yönelik planlanmış faaliyetleri içeren sürekli bir süreçtir. Kalite Geliştirme anlayışı, tek başına yetkinlik yerine pratisyen hekimlerin ve uygulamanın fiili performansına eleştirel bir bakış açısına odaklanmaktadır. ${ }^{1}$

EQuiP Kalite Geliştirme'nin tıp mesleğinin sorumluluğunda olması gerektiği görüşünü savunmaktadır. EQuiP üyeleri kalite geliştirme ve hasta güvenliği konularındaki çalışmalarını, profesyonel bir sorumluluk bakış açısıyla, hasta bakımının tüm yönlerini kapsayan, hasta merkezli, hastanın uygun sağlı bakımı kullanımı arttıran, günlük uygulamanın rutinini, tıp eğitiminin bir parçası olarak, aile hekimliği konusunda spesifik stratejileri olan bir süreç olarak yürütmektedirler. ${ }^{1}$

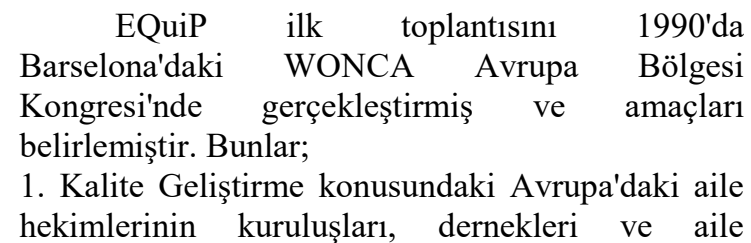

hekimliği akademileri arasındaki işbirliğini teşvik etmek

2. Çalıştaylar organize ederek, raporlar hazırlayarak ve işbirliği projeleri oluşturarak uzman değişimini ve kalite gelişimini teşvik etmek

3. EQuiP çalışmalarını desteklemek için her ülkedeki aile hekimleri, eğitimcileri ve araştırmacıların ulusal ağlarının oluşturulmasını sağlamak

4. Mezuniyet öncesi dönemde, sürekli tıbbi eğitim ve mesleki eğitim programlarına kalite geliştirme konusundaki derslerin yerleştirilmesini sağlamak

5. Kalite geliştirmeyle ilgili çeşitli çalışmalar başlatmak, desteklemek ve danışmanlık yapmak, şeklinde belirlenmiştir. ${ }^{2}$

2003 yllında amaçlar ile ilgili revizyon çalışmaları yapılmıştır. Amaçlar aşağıdaki gibi güncellenmiştir:

1. EQuiP, Avrupa Aile Hekimliği'nde kalite geliştirme ve hasta güvenliği konusunda bilgi ve yenilikler geliştirmeyi ve profesyoneller arasında ağ kurulumunu desteklemeyi amaçlamaktadır.

2. EQuiP, kalite geliştirme ve hasta güvenliği gündeminin WONCA Avrupa'nın temel alanı olmasını sağlamayı amaçlamaktadır.

3. EQuiP'nin görevi Avrupa birinci basamak sağlık hizmetlerinde kalite geliştirme ve hasta güvenliği konusunda eğitim, öğretim ve araştırma alanlarında iyi uygulamaları geliştirmek ve değiştirmektir.

4. EQuiP, Aile Hekimliği'nde kalite ve hasta güvenliğindeki en iyi uygulamaların yürütülmesini sağlamayı ve teşvik etmeyi amaçlamaktadır.

5. EQuiP birinci basamak sağlık hizmetinde kalite geliştirme ve hasta güvenliği konularında WONCA Avrupa için gündemleri belirlemeye ve yönlendirmeye çalışacaktır. ${ }^{3}$

EQuiP dünya çapındaki birinci basamağ1 güçlendirmek için yürüttüğü çalışmalarını Avrupa Sağlık Kayıtları Enstitüsü, Dünya Sağlık Örgütü, Dünya Aile Hekimliği Birliği (WONCA), WONCA Avrupa, European Journal of General Practice dergisi ve Avrupa Aile Hekimliği Araştırma Networkü (EGPRN) işbirliğinde yapmaktadır. ${ }^{1}$

EQuiP'in organizasyonel yapısında bir meclis ve bir yürütme komisyonu yer almaktadır. Yürütme kurulunda başkan, sekreter, sayman WONCA Avrupa Yürütme Kurulu temsilcisi ve 1-3 üye bulunur. Bunun dişında ülkelerin temsilcilerinden oluşan delegeler meclisi de bulunmaktadir. $^{2}$

2006 baharında Türkiye'de yapılan toplantıda, EQuiP tüzüğünün gözden geçirilmesi konusunda karar alınmış ve tüzük taslağ 1 hazırlamak üzere bir grup delege 
görevlendirilmiştir. Taslaklar, İspanya'da 2006 yılında, Çek Cumhuriyeti'nde 2007 yılında, Fransa'da 2007 yılında ve Norveç'te 2008 yılında yapılan dört ardışık toplantıdan sonra, EQuiP meclisi tarafından 8 Kasım 2008'de Bükreş'te kapalı bir toplantıyla kabul edilene kadar tartışılmış ve son haline getirilmiştir. ${ }^{2}$

Halen EQuiP çatısı altında çalışmalar yürüten çalışma grupları da mevcuttur. Bunlar; Esağlık, Eşitlik, Hasta Güvenliği, Kişiselleştirilmiş Bakım, Sosyal medya, Kalite Eğitimi, Göstergeler, Birinci Basamak Sağlik Hizmetlerinde Yapılandırılmış Küçük Grup çalışma gruplarıdır. ${ }^{4}$ $\mathrm{Bu}$ çalışma grupları kendi faaliyet alanlarında çeşitli çalışmalar yürütmektedir. Çalışma grupları farklı ülkelerden, farklı disiplinlerden olan üyelerden oluşmaktadır.

\section{Tarihsel Süreç}

EQuiP'nin organizasyon tarihi üç ana aşamaya ayrilabilir:

1. Ürün aşaması (1991-2006)

2. Yansima evresi (2006-2011)

3. Ağ oluşturma aşaması (2011-şimdi)

\section{Ürün Aşaması (1991-2006)}

Birinci aşama 1991'den 2006 y1lına kadar devam etmiştir. $\mathrm{Bu}$ aşamada ana ilgi odağı birinci basamak sağlık hizmetlerinde kalite geliştirme ve değerlendirme için 'herkese uyan tek beden' araçlar geliştirmekti.

\section{EUROPEP}

EQuiP'nin ilk ürünü, 1995-1999 yıllar1 arasında geliştirilen, hastaların aile hekimliği hizmetini değerlendirmesini sağlayan, uluslararası geçerliliği olan standart bir ölçüm aracı olan EUROPEP (EUROpean Patients Evaluates Patient care)'tir. EUROPEP ölçeği hastaların aile hekimliğinde, bakım kalitesindeki önceliklerini yansıtan bakış açılarını sorgulamaktadır. $\mathrm{Bu}$ nedenle, hasta önceliklerinin yanı sıra bu alandaki literatürün sistematik olarak gözden geçirilmesi için 8 Avrupa ülkesinde (Norveç, İsveç, Danimarka, İngiltere, Hollanda, Almanya, Portekiz ve İsrail) bir anket çalışması yapılmıştır. ${ }^{5,6}$

\section{Olgunluk Matrisi}

21. yüzyıla gelindiğinde, birinci basamakta pratiğe dayalı kalite iyileştirmesini teşvik etmeyi amaçlayan bir örgütsel değerlendirme aracı olan Uluslararası Aile Hekimliği Pratiği Olgunluk Matrisi (IFPMM), EQuiP'den katkı ile olusturuldu. $\mathrm{Bu}$ araç, 1996 ve 2003 yılları arasında Glyn Elwyn ve meslektaşları tarafından geliştirilen İngiltere Maturity Matrix'e dayanıyordu. Araç, örgütsel gelişimi ortaya koyan bir takım örgütsel boyutlardan oluşuyordu. $\mathrm{Bu}$ ölçek kullanılarak yapılan değerlendirmede, bireylerin her bir ölçek boyutunda organizasyonlarının nerede oldukların göstermelerini ve daha sonra bunu bir takım olarak tartışarak, uygulamaları için fikir birliğine vardıkları bir puanı vermeleri gerektirir. ${ }^{7}$

\section{EPA}

Avrupa Uygulama Değerlendirmesi (European Practice Assessment-EPA) birinci basamak sağllk hizmetleri yönetimini değerlendirmek amacıyla 2002-2005 yılları arasında geliştirildi. EPA, kalite göstergeleri kullanarak, iyi uygulamaları vurgulamak için bir akreditasyon sistemi sundu. EPA aracı uzmanlık bilgisi ve rutin günlük uygulama arasındaki boşluğu kapatmak ve iyileştirmenin mümkün olduğu alanları belirlemek de dahil olmak üzere tasarlanmıştır. ${ }^{8}$

\section{Yansıma Evresi (2006-2011)}

Ara dönem 2006-2011 y1lları arasında gerçeklești. $\mathrm{Bu}$ dönemde kalite geliştirme, sağlık sistemleri için karar verme ve planlamada, uygulamanın değişiminde gerekli olan yöntemlere yönelik geliştirilen bireysel araçlar ve bireysel yaklaşımlara odakland1.

PUKÖ (Plan-Do-Study-Act cycles) döngüleri ${ }^{9}$ kullanılarak, küçük ölçekli testler ile ölçme ve bu testlere yapılan geri bildirim ile sağlanan değişimler sonucu ortaya bir gelişme bilimi çıkmıştır.

2007'de Danimarka'dan Tina Eriksson EQuiP'nin 5. başkanlığına geldiğinde, yeni bir çağın geldiğine işaret etti. Bu ikinci aşamada, eğitim kalitesi, EQuiP için yeni bir alan oldu. EQuiP, Aralık 2010'dan Kasım 2012'ye kadar, AB tarafindan finanse edilen inGPinQI projesine ortak olarak katıldı. ${ }^{10}$ Proje sonuçları çağdaş bir teorik çerçeve, uygulamaya yönelik eGuidebook, arteriyel hipertansiyon ve diabetes mellitusun yönetimi için yeni k1lavuzlar [11], e-öğrenme vb. içermektedir.

Aynı dönemde EQuiP Yaz Okulları, kaliteyi araştırmak için yapılandırılmış bir konsept ve oluşturulmuş bir öğrenme platformu haline geldi. Yaz okulları 2009'da Finlandiya'nın Tuusula kentinde başladı ve 2011 yılına kadar Ghent, Belçika'da olmak üzere devam etti. 2013'te iki araştırma kursu (birinde İngilizce, diğeri Fransızca olmak üzere), 2014'te İngiliz Yaz Okulu Danimarka'da yapıldı. 2017 yılında da Paris yakınlarında bir Fransız Yaz Okulu düzenlendi. 


\section{Ă̆ Oluşturma Aşaması (2011-şimdi)}

En son aşama Nisan 2011'de başladı ve halen devam ediyor. $\mathrm{Bu}$ dönemin odak noktası, ürünler yerine paydaşların ve ağların iş birliği ve katılımına yöneldi. Yakın bir örnek, EQuiP'nin 2012-2015 yılları arasında geliştirdiği Kronik Durumlarda Hasta Güçlendirmesi-Wonca Europe (PECC-WE) projesi (Patient Empowerment in Chronic Conditions - Wonca Europe) İstanbul'da düzenlenen Wonca Europe 2015 konferansinda resmi olarak başlatıldı $\mathrm{Bu}$ proje Wonca Avrupa Yıldönümü Araştırma Fonu projesi olarak fonlanmaya hak kazanmış bir projedir. $\mathrm{Bu}$ proje doğrultusunda ortak bir çevrimiçi veri bankası hazırland1.

Hasta güvenliği, aile hekimliğinde kalite gelişiminin yalnızca bir yanı olmakla birlikte, üzerinde konuşulur bir konu haline gelmiştir ve genel pratisyenler için temel bir yetkinlik olarak vurgulanmıştır. $^{12}$ Birçok eski EQuiP temsilcisi tarafindan geliştirilen bu araştırma alanı, tek bir emniyet tedbirini tanımlamak yerine, aynı zamanda ölçütlerin yerel koşullara göre kişiselleştirilmesini ve klinisyenlerin bu tür güvenlik ölçüm araçlarını geliştirmelerini desteklemektedir. ${ }^{13}$

EQuiP'nin hasta güvenliği içerisindeki amac1, birinci basamakta hasta güvenliği konuları olarak; doktor ve personel yorgunluğu ve tükenmişliği ile ikinci ve üçüncü kurban sendromlarına odaklanmaktır, ${ }^{14}$ çünkü bu alan şu an için yeterli farkındalığa, ayrıca iş yükü yoğun olan pratisyen hekimlerin ve sağlık personelinin hasta güvenliği riskini en aza indirgemeyi sağlayacak uygun müdahale stratejilerine sahip değildir. ${ }^{15}$

2015 y1lında EQuiP, Adrian Rohrbasser liderliğindeki Kalite Çemberleri üzerine yeni bir çalışma grubu oluşturdu. Dr Rohrbasser, kalite çemberlerini teşvik eden ve engelleyen, bu iki durumda da ödüllendirici ve değerli olarak algılanan, bağlamsal faktörleri tanımlamaya çalışmaktadır. Mutlaka yeni araç geliştirme ihtiyacı yoktur. Bölgesel veya ülkeye ait bağlam, tarih ve geleneğe bağlı olarak mevcut araçları nasıl kullandığımıza ilişkin kapsamlı bir anlayışa ihtiyaç vardır.

EQuiP ağının tamamı ve sürekli genişletilmesi, gelecekte bu tür değer temelli kalitede kesinlikle önemli bir rol oynamaktadır. Ağustos 2017 itibarıyla, EQuiP, 25 Avrupa ülkesinden 95 aktif ve özel üyeye sahiptir.

EQuip üye sayısının gittikçe arttırmaktadır. Yılda iki defa yapılan kongreleriyle ve farklı kongrelerde EQuip olarak yaptığı katkılar ve katılımlar ile etkinlik alanını genişletmektedir.

\section{KAYNAKLAR}

1. From closed quality group to open network. Edition: June 2016 http://equip.woncaeurope.org/sites/equip/f iles/Documents/EQuiP_June2016.pdf (giriş 20.12.2017)

2. Ortiz JMB. Short history of EquiP. http://equip.woncaeurope.org/members/sh ort-history-equip(giriş 20.12.2017)

3. EQuiP Constitution, Version Approved 5ThApril

2013

http://equip.woncaeurope.org/about/consti tution(giriş 20.12.2017)

4. Working Groups of EquiP. http://equip.woncaeurope.org/8-workinggroups (giriş 20.12.2017)

5. Grol R et al. Patients' priorities with respect to general practice care: an international comparison. European Task Force on Patient Evaluations of General Practice (EUROPEP). Family Practice 1999;16:4-11.

6. Wensing M, Jung HP, Mainz J, Olesen F, Grol R. A systematic review of the literature on patient priorities for general practice care. Soc Sci Med 1998;47:157388.

7. Edwards A et al. Assessing organisational development in European primary care using a group based method: A feasibility study of the Maturity Matrix. Int J Health Care Qual Assur 2010;23:8-21.

8. Szecsenyi J. et al. Effectiveness of a quality-improvement program in improving management of primary care practices.CMAJ 2011;18(3):1326-1333

9. de Koning H, Verver JP, van den Heuvel J, Bisgaard S, Does RJ. Lean six sigma in healthcare. J Health Qua 2006;28:4-11.

10. InGPinQI: Innovative lifelong learning of European General Physicians in Quality Improvement supported by information technology 2012. Available at: http://ingpinqi.eu/ (giriş 18.07. 2016).

11. Tomasik T, Windak A, Seifert B, Kersnik J, Jozwiak J. Treatment targets in patients with Type 2 diabetes set by primary care physicians from Central and Eastern Europe. Eur J Gen Pract. 2014;20:253-59.

12. Eur $\mathbf{J}$ Gen Pract. Patient safety in primary care (supplement issue). 2015;21:1-77.

13. Vincent C, Esmail A. Researching patient safety in primary care: Now and in the future. Eur J Gen Pract 2015;21:1-2.

14. Second and Third Victim Research Group. Recommendations for providing 
an appropriate response when patients experience an adverse event with support for healthcare's second and third victims 2015. Available at: http://www.segundasvictimas.es/data/doc umentos/segundas_victimas_maquetacion ingles_impresion_v06.pdf (giriş 18.07. 2016).

15. Royal College of General Practitioners. Patient safety implications of general practice overload 2015. Available at: http://www.rcgp.org.uk/policy/rcgppolicy-areas/ /media/Files/Policy/A-Zpolicy/2015/RCGP-Patient-safetyimplications-of-general-practiceworkload-July-2015.ashx (giriş 20.07. 2016). 